\title{
Experimental Study on the Blasting Performance of Water-Soil Composite Stemming in Underground Mines
}

\author{
Xianyang Qiu $\mathbb{D}^{D}$, Xiuzhi Shi $\mathbb{D}^{D}$, Shu Zhang ${ }^{D}$, Bo Liu, and Jian Zhou $\mathbb{D}^{\mathbb{D}}$ \\ School of Resources and Safety Engineering, Central South University, Changsha 410083, China \\ Correspondence should be addressed to Xiuzhi Shi; csublasting@163.com and Shu Zhang; zhangshu@csu.edu.cn
}

Received 28 November 2017; Accepted 27 December 2017; Published 7 March 2018

Academic Editor: Andrey E. Miroshnichenko

Copyright ( 2018 Xianyang Qiu et al. This is an open access article distributed under the Creative Commons Attribution License, which permits unrestricted use, distribution, and reproduction in any medium, provided the original work is properly cited.

\begin{abstract}
Top stemming is necessary to stop the explosive energy from escaping through the upper part of blast-holes in cutting blasts of large-diameter deep-hole blasting in underground mines. The often-used single soil stemming frequently leads to material clogging which results in reduction of blasting efficiency. In this paper, a new water-soil composite stemming is proposed to solve the problem. A series of small-scale tests were conducted on solid concrete masonry blocks to investigate the effect of top stemming material and stemming length on blasting performance. The experimental results indicated that water stemming was worse at improving the utilization rate of the explosion energy compared with single soil stemming of the same length. Further, the mean fragment size decreased with the increase of stemming length for single water stemming. Three schemes of water-soil composite stemming were designed and the scheme with soil in the lower part and water filled in bags in the higher part had the best fragmentation. The water-soil composite stemming was applied in underground stopes, and field results indicated that the newly proposed stemming led to similar rock fragmentation with traditional single soil stemming, but greatly reduced the clogged blast hole ratio, thus effectively improving blasting and mining efficiency.
\end{abstract}

\section{Introduction}

Hard rock fragmentation by blasting is an extensive and effective practice in the engineering of mines and quarries [1-3]. Utilization efficiency of energy from the explosive has a profound impact on rock fragmentation and subsequent mucking and transportation. Researchers have been trying to utilize more energy released during blasting for rock breaking but less for air shock waves and ground vibration $[4,5]$. It is commonly agreed that energy released during blasting spreads into surrounding rock through two types of loadings: shock wave (stress wave) and explosion gas pressure [6-8]. The stress wave initiates cracks around the blast hole and near free surface, and the longer duration gas pressure penetrates these initial cracks and causes their further extension, finally driving the movement of fractured rocks $[9,10]$.

Generally, blast holes from the explosive charge at the mouth of the hole are stemmed with inert materials to optimize the usage of explosive energy and reduce unnecessary discharge [11]. Due to adequate stemming, the efficiency of blasting increases nearly $50 \%$, which has been proven by both lab and field tests [12]. Missing or improper stemming, which leads to detonation gas escaping from blast holes in advance, results not only in wastage of explosive energy and poor fragmentation but also in environmental problems, such as ground vibration, noise, flying rocks, back breaks, and air blasts [13]. Previous research showed that stemming can increase the action time of detonation gas inside the blast holes (Figure 1) and promote the full reaction of explosives, reducing explosive consumption $[14,15]$.

In mining industries, three types of materials, including solid, liquid, and colloidal materials, are used as stemming materials in blast holes. Scholars have not yet made sufficient progress on the selection of stemming materials. Li et al. [16] indicated that water stemming, consisting of polyvinyl plastic bags filled with water, which are stemmed inside blast 


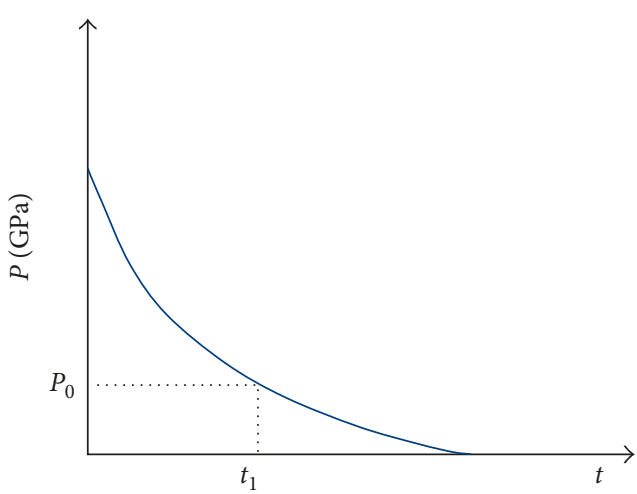

(a)

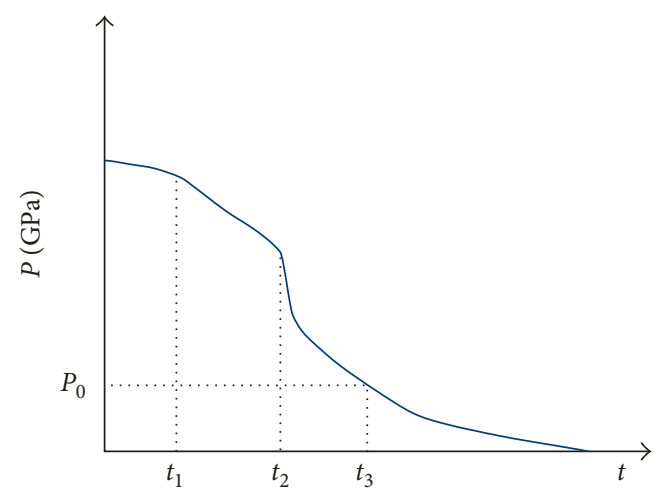

(b)

FIgURE 1: The curves of pressure and time: (a) without stemming; (b) with stemming.

holes, can effectively reduce blasting-induced dust content. Cevizci [17] compared a newly developed plaster stemming with conventional stemming with "dry drill cuttings," and finer fragmentation was obtained by plaster stemming. Cui et al. [18] proposed a water-silt composite-stemmed blasting method in tunnels, which could improve the breakage of rock, lower dust, and save explosive. Cui [19] also studied the influence of water-silt composite blasting on the stability of rocks surrounding a tunnel. Sharma and Rai [20] assessed the influence of crushed aggregate stemming and drill cuttings material on blasting performance. Manoj et al. [21] proposed an environment-friendly blasting technique, in which discarded water bottles were used.

The process of ejection of stemming material from a blast hole is strongly dependent on the length of stemming material. Currently, there are a number of documents devoted to studying the effect of stemming length in blasting [22-24]. Most adopted theoretical studies, field tests, and numerical studies, but few model tests, were implemented. Cevizci and Ozkahraman [22] studied the effect of stemming length on muckpile size distribution and showed that the large size boulder formation is increased rapidly by choosing a stemming length longer than that necessary. Li and Liu [23] derived the computational formula of stemming length in one-step deep-hole blasting using momentum theory. Wang et al. [24] studied the blast hole stemming length effects of rock blasting with a parallel double free surface using LS-DYNA. This study will focus on the stemming effect on blasting performance through model tests.

Large-diameter deep-hole blasting technology is widely applied in underground mines due to its high efficiency [25]. The downward blast holes are drilled all at once, but because of a lack of free surfaces, several cutting blasts are carried out to form the free surface and provide compensation space for subsequent breaking blasts, as shown in Figure 2. Therefore, top stemming (normally soil is used) above the upper explosive in each cutting blast is needed to stop the explosive energy from escaping through the upper part of the blast holes. If the top stemming is too short, explosive energy will be wasted and the blast holes will be destroyed, which is adverse to the subsequent blasts. If the top stemming is too long, the stemming material will be clogged inside the blast holes because of the compression effect of the explosion pressure, which leads to additional time and work to handle the clogged blast holes and reduction of blasting and mining efficiency. In this paper, a new water-soil composite stemming is proposed to solve the problem of top stemming clogging. In this stemming scheme, top stemming is partly replaced by plastic bags filled with water. After the detonation of an explosive, bags are broken under explosion pressure and water outflows from the bags and scours the soil. With the help of water, soil will not be clogged inside the blast holes. In the present study, model tests are first carried out to investigate the effect of top stemming material on blasting performance. Then, the newly proposed water-soil composite stemming is applied in underground stopes in the Fankou lead-zinc mine in China.

\section{Experimental Setup}

2.1. Block Preparation. A series of small-scale tests were made on solid concrete masonry blocks. The blocks are made of rod-mill sand with a diameter $1-5 \mathrm{~mm}$, high-strength Portland cement, and water. The concrete blocks with the same material ratio have provided excellent results in rock blasting tests [26]. The average density is $2,250 \mathrm{~kg} / \mathrm{m}^{3}$, the elastic modulus is $21 \mathrm{GPa}$, the compressive strength is 39.27 MPa, the tensile strength is $2.82 \mathrm{MPa}$, the P-wave velocity is $3,580 \mathrm{~m} / \mathrm{s}$, and Poisson's ratio is 0.29 .

In order to eliminate the free boundary effect of the concrete block, a size test was carried out, and the block dimension in this study was confirmed to not affect the test results significantly. The blocks were prepared with sizes of $50 \mathrm{~cm} \times 50 \mathrm{~cm} \times 20 \mathrm{~cm}$, as shown in Figure 3. Four blast holes were set in the middle of the blocks. The diameter of the blast holes is $15 \mathrm{~mm}$, and the depth is $20 \mathrm{~cm}$. The blast holes are arranged as squares, and the spacing is $7 \mathrm{~cm}$, as shown in Figure 4 . The explosive source used in this study was detonating cord with a diameter of $5 \mathrm{~mm}$ and a detonation velocity of $7,000 \mathrm{~m} / \mathrm{s}$, giving a specific charge of $1.26 \mathrm{~g} / \mathrm{cm}^{3}$. The initiating explosive was ordinary \#8 detonator with a diameter of $6 \mathrm{~mm}$, giving $0.6 \mathrm{~g}$ DDNP and RDX each. The detonating cord was tied with an industrial detonator by glue, as shown in Figure 5. Single blast hole tests 


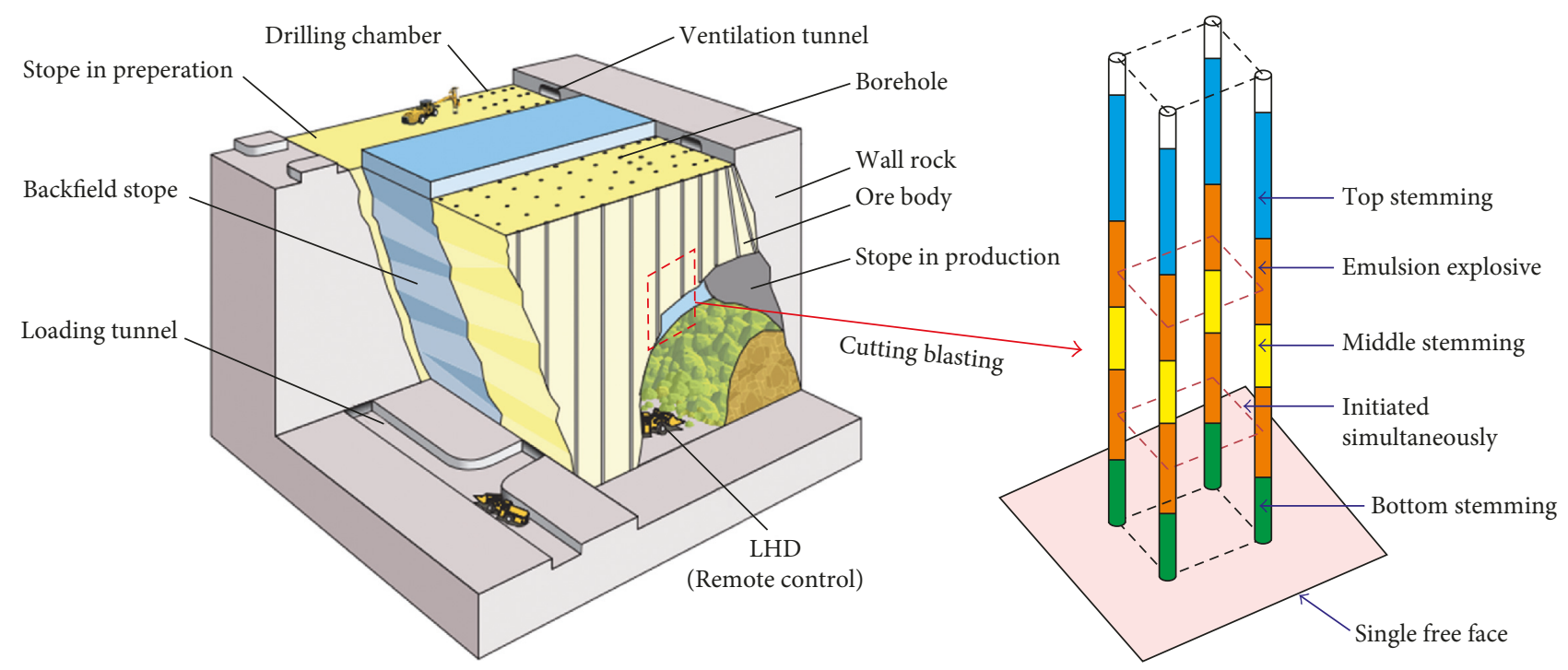

Figure 2: Cutting blasting in large-diameter deep-hole mining technology.

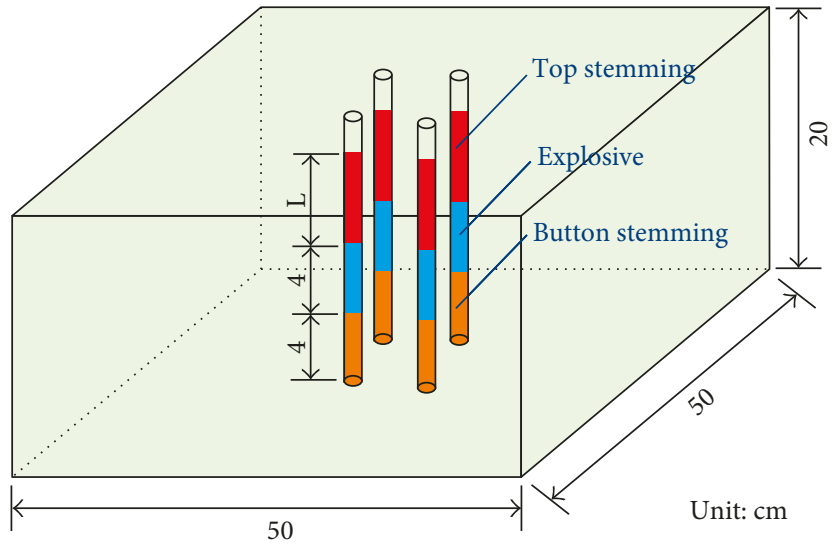

Figure 3: Diagram of experimental blocks.

with different lengths of detonating cord were performed, and for the purpose of obtaining an appropriate blasting crater, the length of detonating cord finally selected was $4 \mathrm{~cm}$.

2.2. Stemming Scheme. The explosive with a length of $4 \mathrm{~cm}$ was centred at $6 \mathrm{~cm}$ above the bottom surface, which means the bottom and top burdens were 4 and $12 \mathrm{~cm}$, respectively. This study mainly focused on the effect of top stemming on blasting. Thus, the bottom of the blast holes was uniformly stemmed with silt, which is used to fix the explosive. The average density of the silt is $1,800 \mathrm{~kg} / \mathrm{m}^{3}$. The top of the blast holes was stemmed with three types of materials: soil that was used in the underground mine, water that was filled in polyvinyl plastic bags with different lengths as shown in Figure 6, and water-soil composite stemming. The diameter of the plastic bags filled with water is $13 \mathrm{~mm}$, slightly less than the diameter of the blast holes so as not to cause breakage of the bags due to the friction of the bags with the hole wall. The average density of the soil is $1,600 \mathrm{~kg} / \mathrm{m}^{3}$.
2.3. Measured Data. The blasting performance was assessed by the size of the blasting crater, length of the cracks, and size distribution of the fragments after blasting. Typical blasting performance is shown in Figure 7. It can be seen that because of the shorter burden, both perfect blasting craters and macrocracks were obtained in the bottom surface of the block, but only macrocracks were found in the top surface of the block as the burden was longer. The cracks were divided into two categories: main cracks, which were extended along the corners of the blocks, and branch cracks, which were extended perpendicular to the boundaries of the blocks. The role of top stemming was to prevent the explosive energy escaping from the upper blast hole, which could lead to wasting of explosive energy [16]. Hence, the bigger the blasting crater and the more uniform the fragments in the bottom surface of the block, the higher the utilization rate of explosive energy is. The more the cracks extended in the top surface of the block, the lower the utilization rate of explosive energy is. Thus, the diameters of blasting craters and the lengths of macrocracks for the blocks were measured carefully after blasting. Furthermore, blasting-induced fragments were weighed according to different particle sizes.

2.4. Testing Procedure. The tests were divided into three stages. First, the tests for blocks with soil and water stemming with the same length were carried out to compare the blasting performances of the two different stemming materials. Then, blasting for blocks with water stemming with different lengths was conducted to investigate the influence of the water length on blasting performance. Finally, several water-soil composite stemming schemes were proposed and compared with the traditional single material stemming.

\section{Results and Analysis}

3.1. Comparison of Soil and Water Stemming. Blasting tests for water and soil stemming with a length of $8 \mathrm{~cm}$ above the 

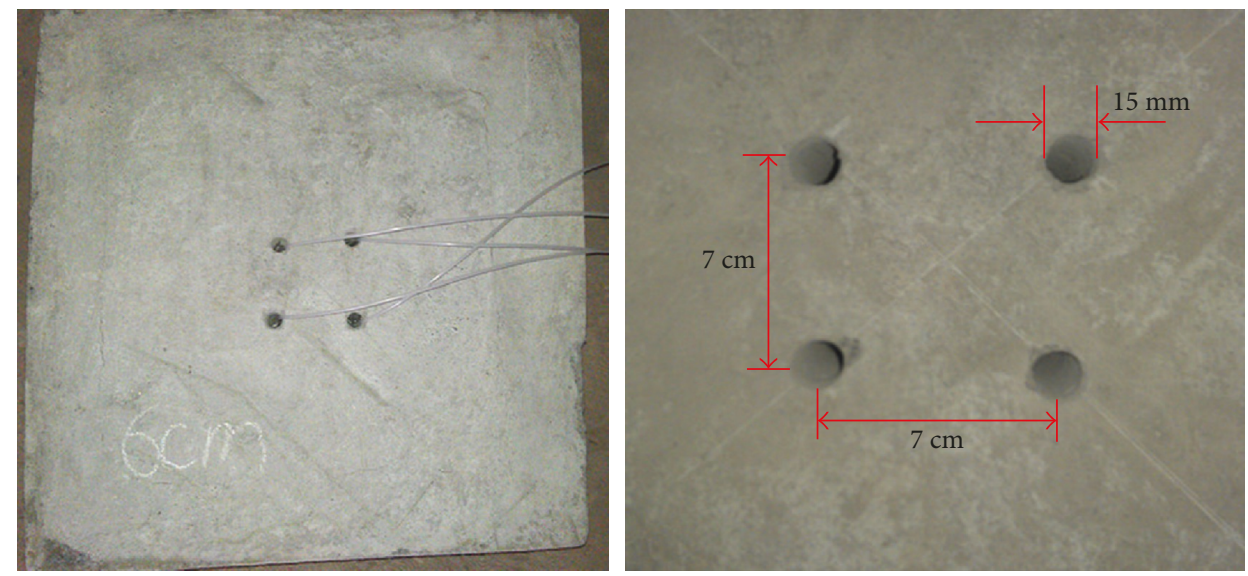

FIGURE 4: Diagram of blasting-hole arrangement in blocks.
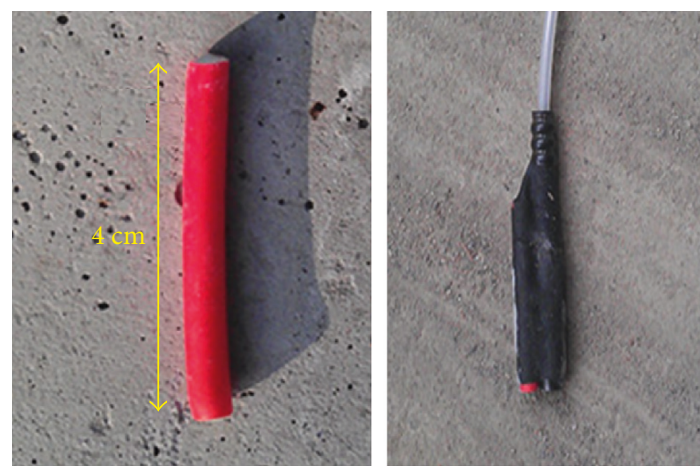

FIgURe 5: Explosive for the experiments.
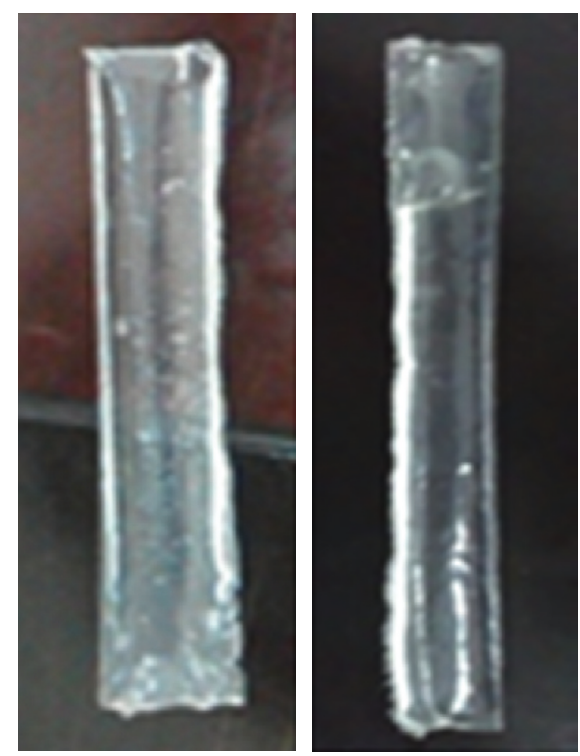

Figure 6: Water stemming filled in plastic bags.

explosive were contrastively conducted. The blasting craters in the bottom surface and cracks in both the bottom and top surfaces are shown in Figure 8. The blasting crater for soil stemming was larger than water, and soil stemming caused more damage in the top surface than water. Figure 9 shows the cumulative fragment size distribution curves of water and soil stemming. As shown, water stemming had coarser fragmentation than soil stemming. The largest fragment sizes for soil and water stemming were 7 and $8 \mathrm{~cm}$, respectively.

The test results indicate that the explosive energy for soil stemming is utilized more effectively in breaking rock in the bottom direction and more energy for water stemming is wasted in the top direction of the model. This is partly because the diameter of the bags filled with water is slightly less than the diameter of the blast holes, which may cause part of the detonation gas ejecting early from top blast holes. Excluding this factor, we can safely draw a conclusion that, compared with water stemming with same length, soil stemming is better at increasing the action time of detonation gas inside blast holes and improving the utilization rate of explosion energy.

3.2. Effect of Length of Water Stemming. To investigate the influence of the water length on blasting performance, five blocks with different lengths of water stemming, containing $3 \mathrm{~cm}, 4 \mathrm{~cm}, 6 \mathrm{~cm}, 8 \mathrm{~cm}$, and $10 \mathrm{~cm}$, were performed. The blasting craters in the bottom surface and cracks in both the bottom and top surfaces are presented in Figure 10. With the increase of the length of water stemming, the blasting crater in the bottom surface of the models was bigger. For the case of $3 \mathrm{~cm}$, it failed to form a shaped blasting crater, and for the case of $10 \mathrm{~cm}$, there was a perfect blasting crater in the bottom surface. Then, in the top surface of the block, there were nearly no damage for the case of $3 \mathrm{~cm}$, and little damage for the case of $4 \mathrm{~cm}$. This is consistent with our conventional understanding that exceedingly short stemming leads to shorter action time of detonation gas inside blast holes, and then less energy can be used to break rock, both in the bottom and top directions of the model. Thus, stemming that is too short should be avoided in practical blasting.

As shown in Figure 10, cracks extended in the top surfaces of $6 \mathrm{~cm}$ and $8 \mathrm{~cm}$ cases, indicating that more damage was caused compared with the $10 \mathrm{~cm}$ case, which could be further proved by the average length curves of the cracks in both the bottom and top surfaces, as shown in 


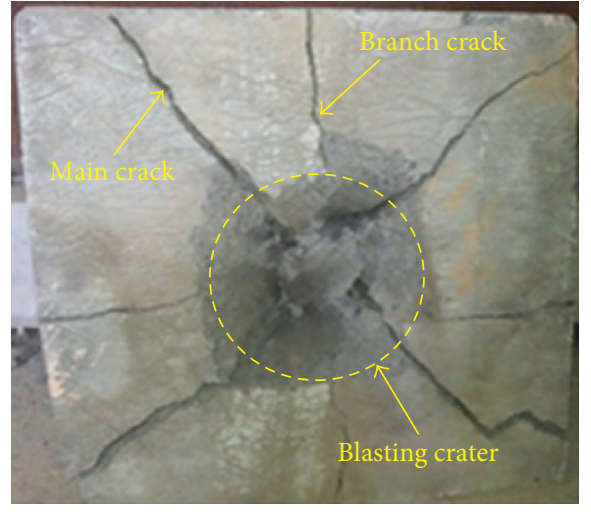

(a)

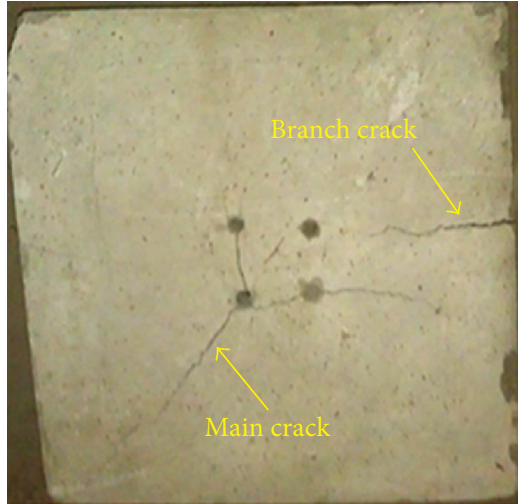

(b)

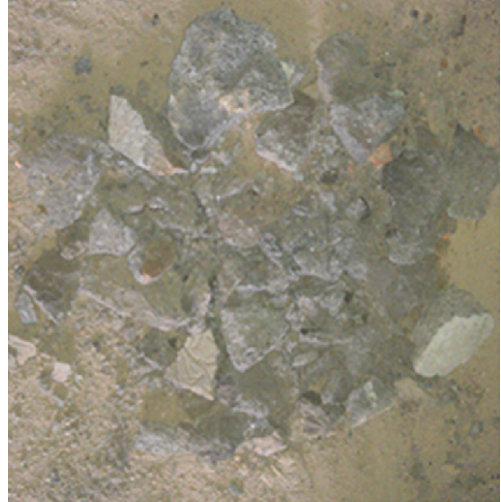

(c)

FIgURE 7: Typical blasting performance: (a) bottom surface; (b) top surface; (c) fragments after blasting.
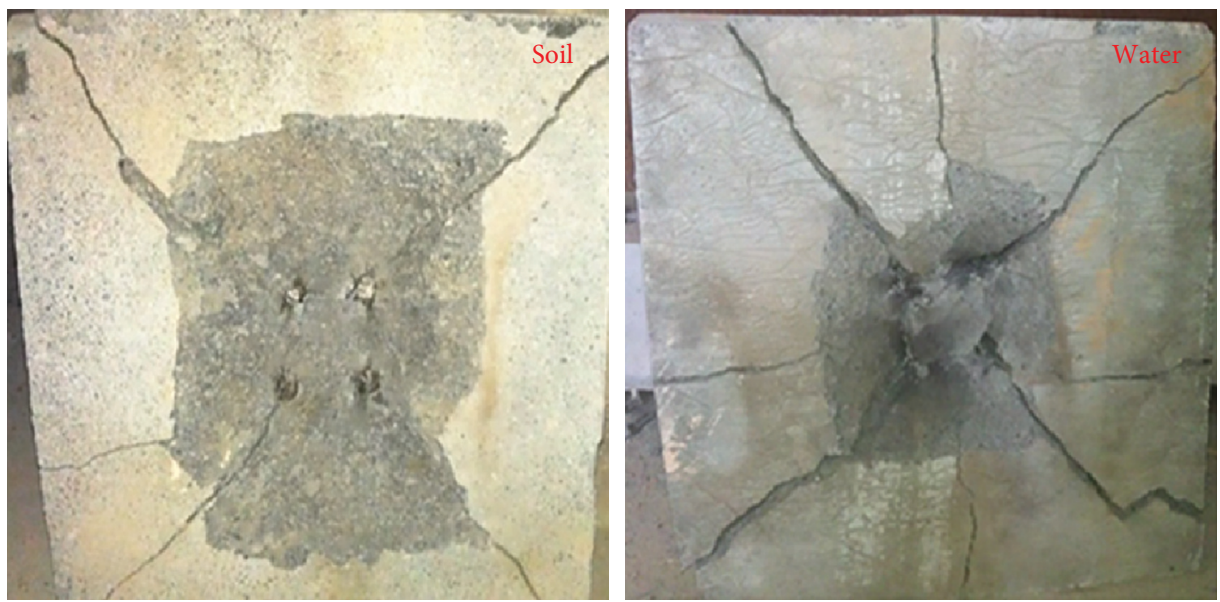

(a)
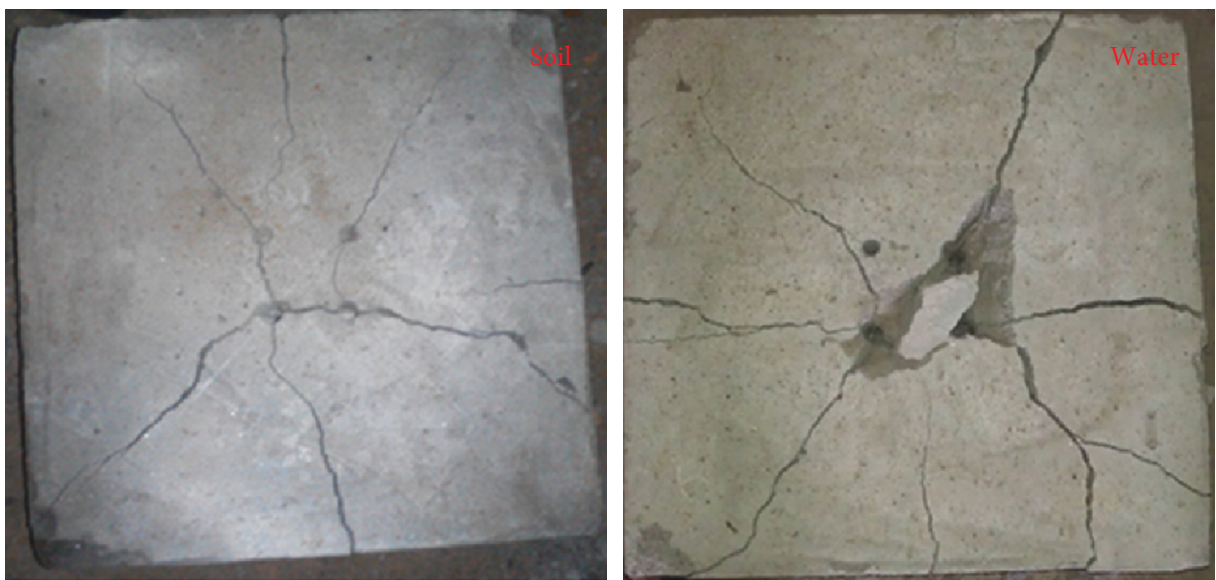

(b)

Figure 8: Comparison of blasting performances of soil and water stemming: (a) bottom surface; (b) top surface.

Figure 11. This implies that most explosive energy for water stemming with a length of $10 \mathrm{~cm}$ is utilized effectively for rock breaking in the bottom direction. It is also observed from Figure 12 that the best fragmentation was found for water stemming with a length of $10 \mathrm{~cm}$. Cases of $3 \mathrm{~cm}$ and
$4 \mathrm{~cm}$ also had good fragmentation, which was inconsistent with our conventional understanding. The reason was that the blasting craters for cases of $3 \mathrm{~cm}$ and $4 \mathrm{~cm}$ were too small, for which large blocks were impossible. However, for cases of water stemming lengths from 6 to $10 \mathrm{~cm}$, we 


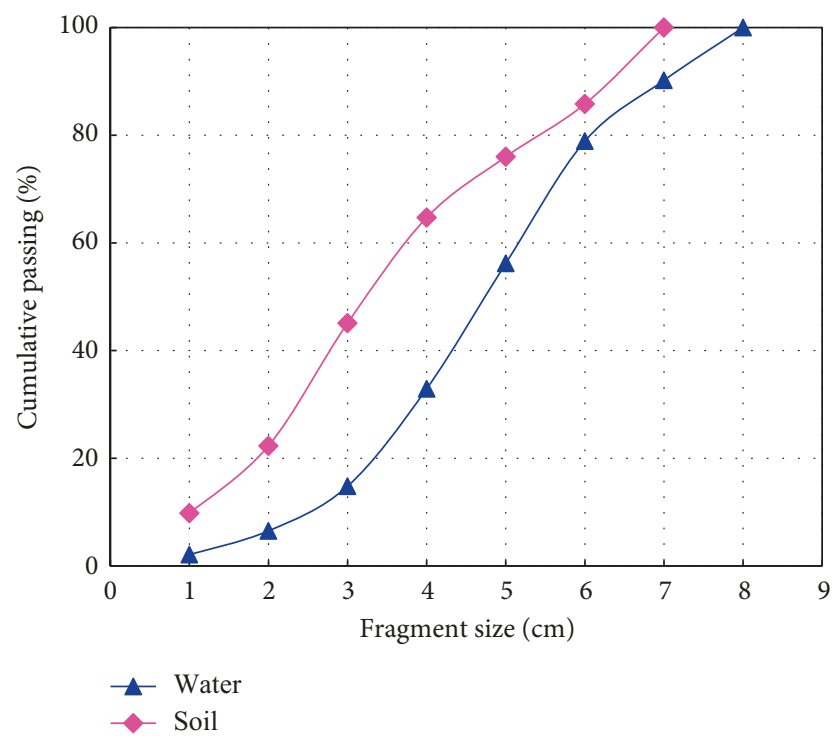

FIgURE 9: Fragment size distribution of soil and water stemming.
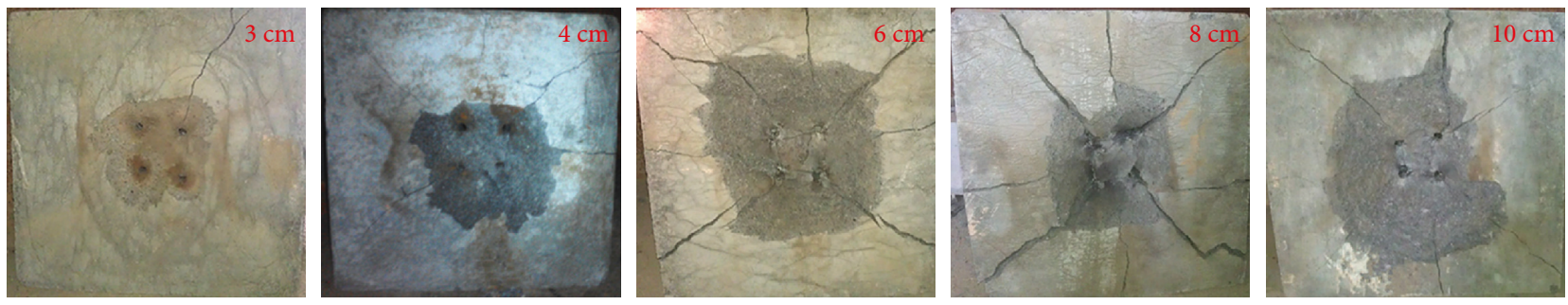

(a)
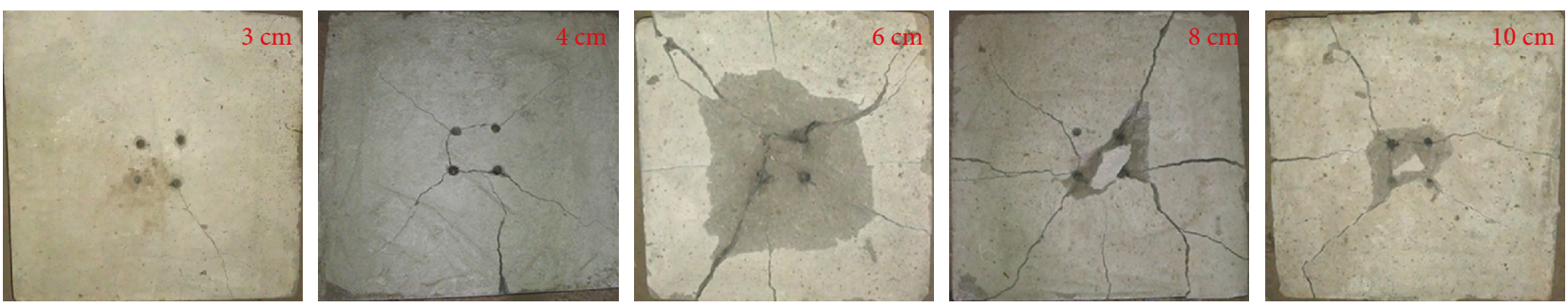

(b)

FIGURE 10: Comparison of blasting performances of water stemming with different lengths: (a) bottom surface; (b) top surface.

found that the mean fragment size decreased with an increase of stemming length.

3.3. Effect of Water-Soil Composite Stemming. To solve the problem of top stemming clogging, three schemes of watersoil composite stemming were designed and compared with the traditional single soil stemming. It is impossible to model the clogging process by experimental tests. Thus, this test mainly focuses on the blasting performance of the newly proposed stemming schemes. As presented in Figure 13, details of the three types of top stemming are as follows: scheme 1 is soil with a length of $4 \mathrm{~cm}$ in the lower part and water filled in bags with a length of $4 \mathrm{~cm}$ in the higher part; scheme 2 is water filled in bags with a length of $4 \mathrm{~cm}$ in the lower part and soil with a length of $4 \mathrm{~cm}$ in the higher part; scheme 3 is soil with a length of $2 \mathrm{~cm}$ in the lower part, water filled in bags with a length of $4 \mathrm{~cm}$ in the middle part, and soil with a length of $2 \mathrm{~cm}$ in the higher part.

The blasting craters in bottom surface and cracks in both bottom and top surfaces for water-soil composite stemming are shown in Figure 14. It is observed from Figure 14 that scheme 1 had the largest blasting crater. Scheme 2 and 3 had similar blasting craters and extended cracks. In addition, some soil was found in the top surface of the concrete block for scheme 2 . This is because the diameter of the plastic bags filled with water in the lower part was less than the blast hole. This uncoupling characteristic resulted in a part of the explosive energy pushing the soil out of the blast hole in advance. The fragment size 


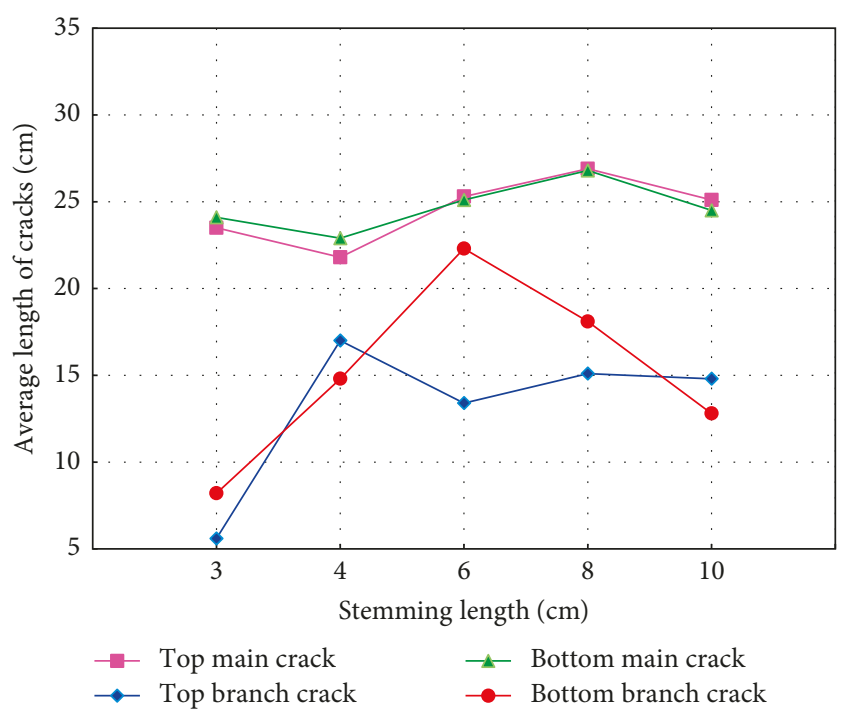

Figure 11: Cracks' lengths of water stemming.

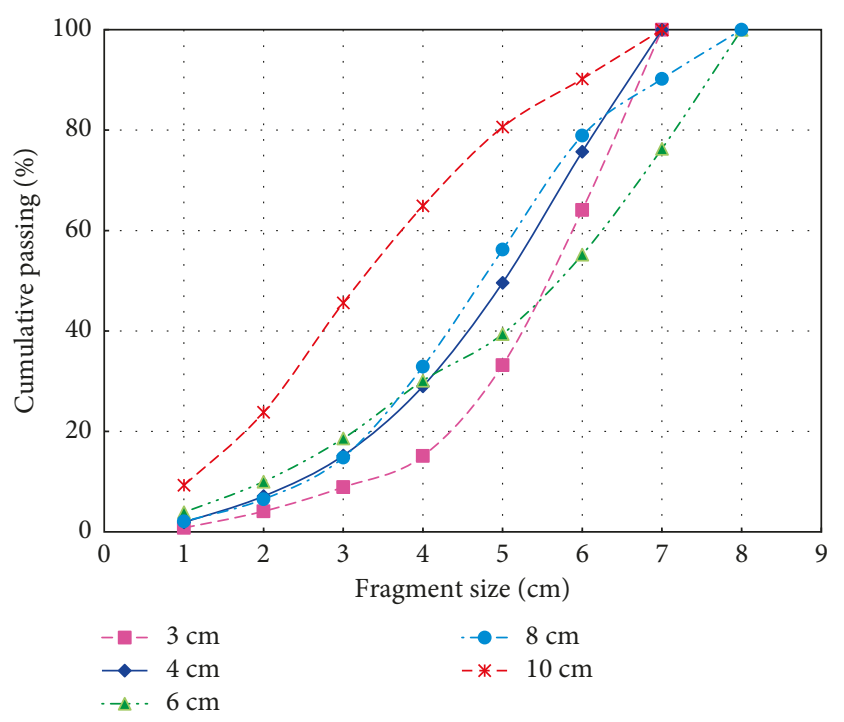

Figure 12: Fragment size distribution of water stemming.

distributions of water-soil composite stemming were compared with single soil stemming with a length of $8 \mathrm{~cm}$, as shown in Figure 15. We can see that scheme 1 had similar fragmentation with single soil stemming, and scheme 3 had the worst fragmentation.

Therefore, scheme 1 with water-soil composite stemming was selected to replace the traditional single soil stemming, and the feasibility of reducing top stemming clogging of blast holes through the application of the new stemming scheme was needed by field tests.

\section{Field Experiments in Underground Mine}

4.1. Description of the Experimental Site. The Fankou leadzinc mine, in which mining began in 1968, is one of the largest underground mines in China. The mine is in the southwest of Shaoguan city in the Guangdong province in

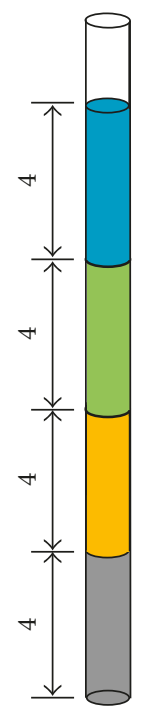

Scheme 1

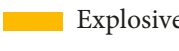

Soil

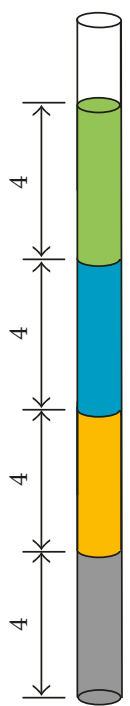

Scheme 2

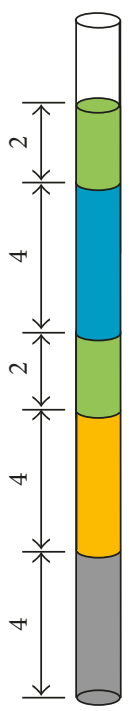

Scheme 3
FIGURE 13: Schemes of water-soil composite stemming (unit: $\mathrm{cm}$ ).

China. The annual ore quantity is $1,500 \mathrm{kT}$, with average grade lead $4.89 \%$ and zinc $9.12 \%$. The ore body lies in carbonate rocks and appears in near-bedded and lenticular shapes with a buried depth more than $900 \mathrm{~m}$. There are three main ore blocks: Jinxingling, Shiling, and Shilingnan. Field tests in the present study were carried out at the Shiling ore block, with a strike length of $1,350 \mathrm{~m}$. The dip angle of the ore body is $25-53^{\circ}$, normally $45^{\circ}$. The thickness of the ore body is from maximum $46 \mathrm{~m}$ to minimum $4 \mathrm{~m}$, with average $13.7 \mathrm{~m}$.

Large-diameter deep-hole mining technology is the main mining method in Fankou lead-zinc mine, which fulfils the production of ore quantity $600 \mathrm{kT}$, accounting for approximately $40 \%$ of the total. Down-hole drill machines are used to drill downward blast holes with large diameter and high depth. As shown in Figure 2, because of the lack of free surfaces, cutting blasting is carried out to form the free surface and provide compensation space for subsequent breaking blasts. Underground remote control LHD machines are used to shovel and transport broken rocks in the bottom chamber.

4.2. Scheme of Field Experiments. Blasts were carried out in two different stopes at the $-600 \mathrm{~m}$ level of the Shiling ore block to contrastively investigate the blasting performance for different stemming materials. The two stopes are both column stopes which are surrounded by back fillings. The two stopes are in the same region with similar ore and rock conditions and identical blasting parameters. Six cutting blasts and two subsequent breaking blasts were carried out in these two topes, respectively. The field experiments in the present study focus on the cutting blasts, which all face the problem of top stemming.

As shown in Figure 16, stope 1 conducted the soil stemming case, which was used in previous blasts in this 

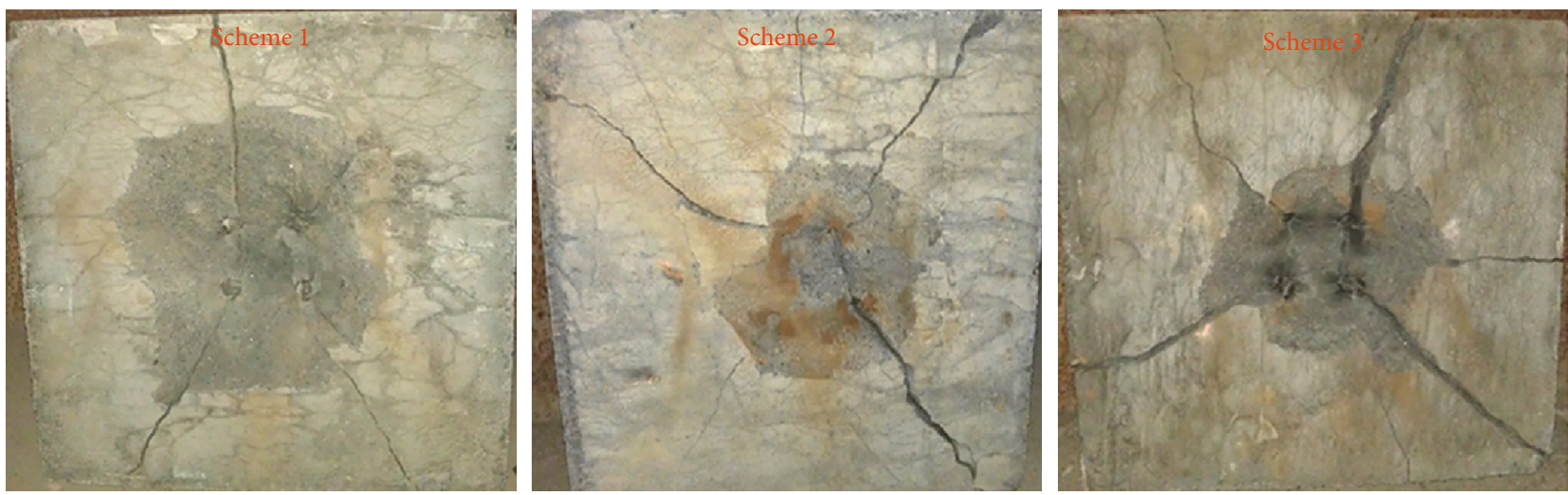

(a)
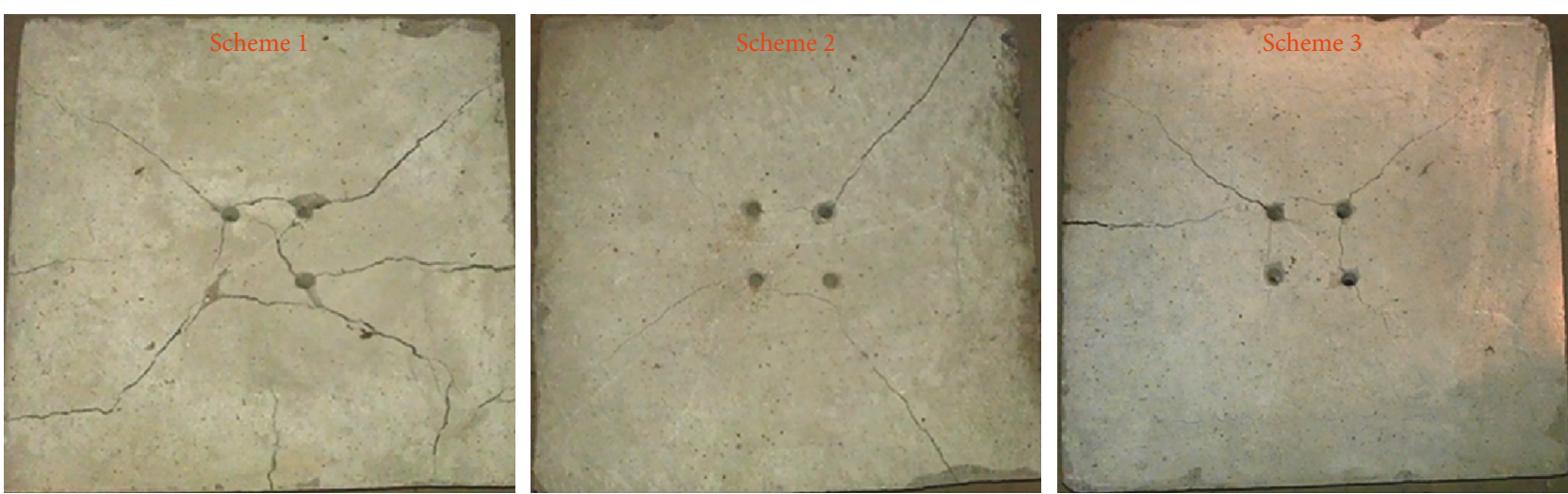

(b)

FIGURE 14: Comparison of blasting performances of water-soil composite stemming: (a) bottom surface; (b) top surface.

mine, and stope 2 conducted the water-soil composite stemming case. The diameter and height of blast holes is $110 \mathrm{~mm}$ and approximately $40 \mathrm{~m}$. The spacing is $2 \mathrm{~m}$, and the burden is $2.2 \mathrm{~m}$. The height for each blast is approximately $5.5 \mathrm{~m}$. The number for each blast is approximately 30 . Emulsion explosive and pyrotechnic detonators were used in this study. The charging structures of these two stopes are presented in Figure 17. Normally, two segments of explosives were placed in a blast hole. Delay between blast holes for the same layer was $25 \mathrm{~ms}$, and delay between the two segments of explosives in one blast hole was approximately $200 \mathrm{~ms}$.

Soil with a length of $1.2 \mathrm{~m}$ was stemmed in the bottom of blast holes, and explosive with a length of $1.5 \mathrm{~m}$ was placed above the soil. Then, soil with a length of $1.2 \mathrm{~m}$ was stemmed as middle stemming, and the explosive with a length of $1.5 \mathrm{~m}$ was placed above it. The top stemming for the two stopes were different: stope 1 was soil with a length of $2 \mathrm{~m}$, and stope 2 was soil with a length of $1 \mathrm{~m}$ in the bottom and water filled in bags with length of $1 \mathrm{~m}$. The diameter of water bags was $105 \mathrm{~mm}$, slightly less than the blast holes.

4.3. Experiment Results. After each blast, broken rocks were shovelled and transported by similar machines, as shown in Figure 18, and the weights of the first six cutting blasts were carefully measured. It is impractical to obtain a detailed

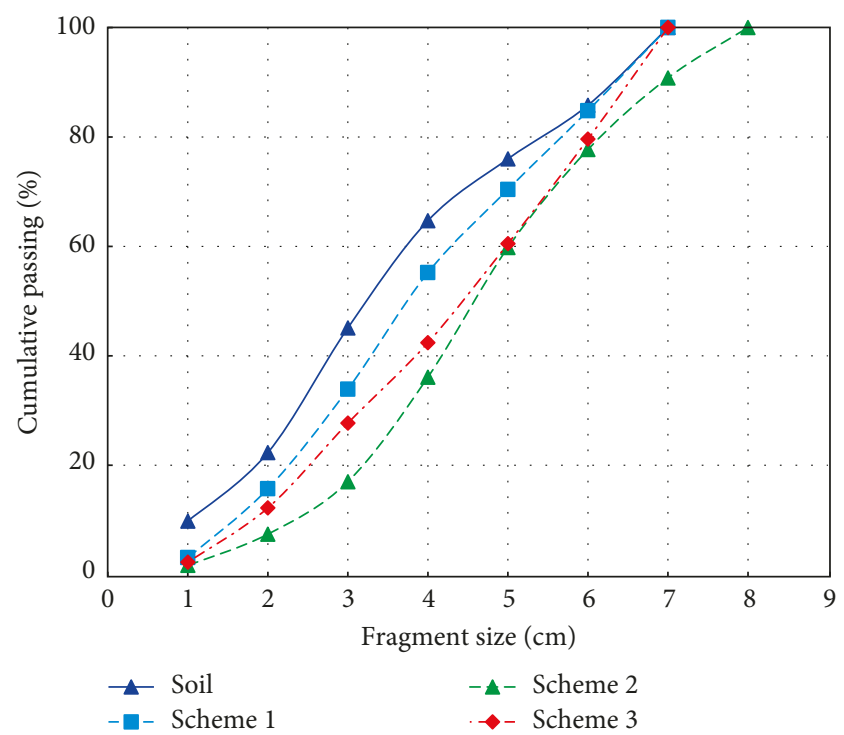

FIGURE 15: Fragment size distribution of water-soil composite stemming.

fragment size distribution in field blasting in underground mines. Therefore, a large block ratio was used to assess the rock fragmentation induced by blasting. Large blocks, which are defined as blocks with single lengths of more 


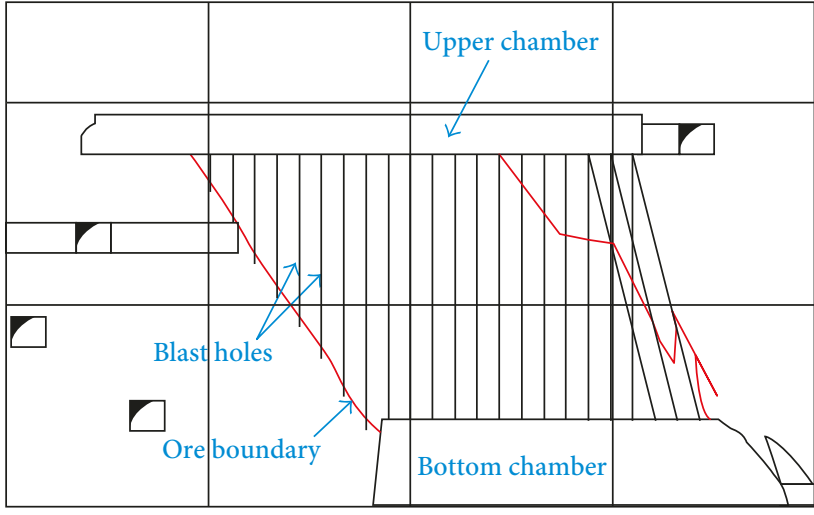

(a)

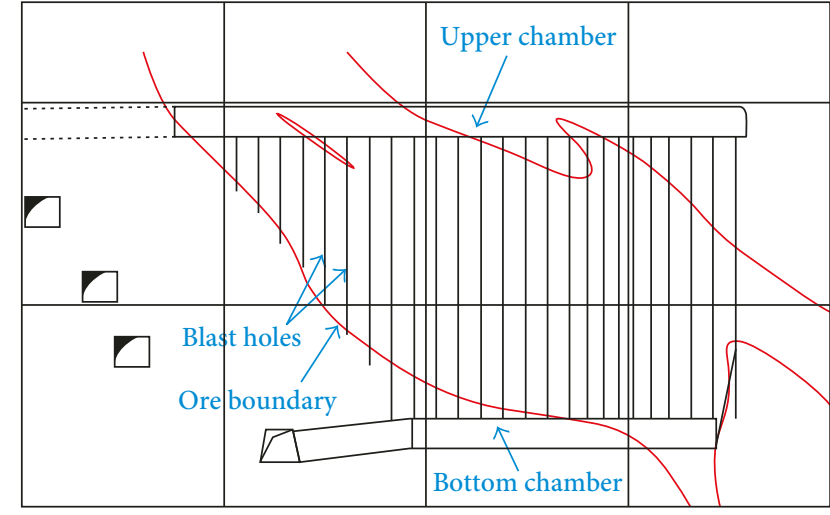

(b)

Figure 16: Testing stopes: (a) stope 1; (b) stope 2.

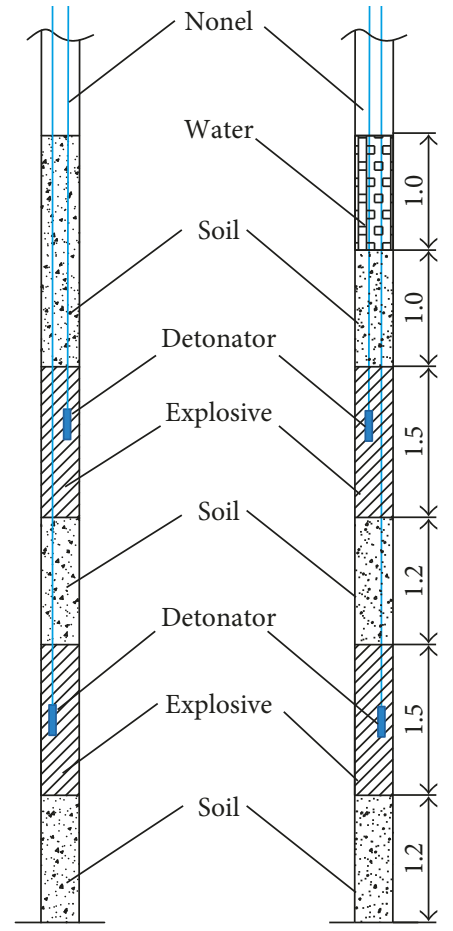

(a)

(b)
FIGURE 17: Charging structures of cutting blasting: (a) stope 1; (b) stope 2 .

than $0.7 \mathrm{~m}$ in the mine, were sorely handled and secondarily broken. The large block ratios versus blasting times for these two stopes are plotted in Figure 19. It appears from Figure 19 that similar large block ratios were found for different top stemming schemes. Thus, it can be said that the newly proposed water-soil composite stemming did lead to similar rock fragmentation compared with traditional single soil stemming.

Figure 20 depicts the clogged blast hole ratio after blasting versus blasting times. It is observed from Figure 20 that the clogged blast hole ratios for stope 1 with single soil

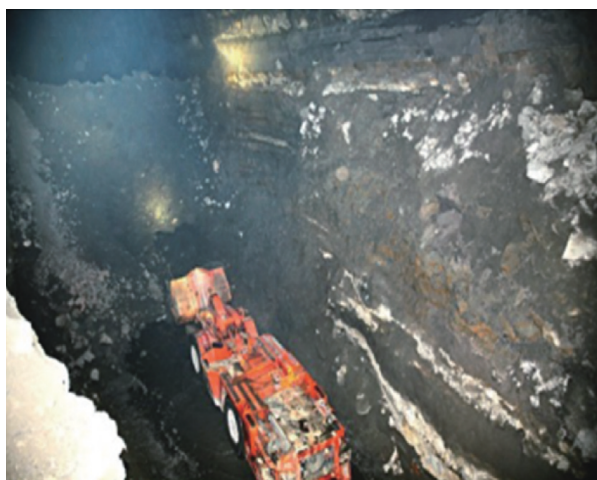

(a)

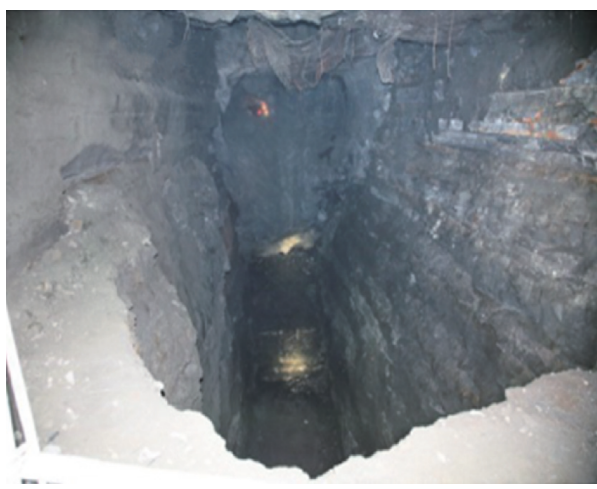

(b)

FIGURE 18: Charging structures of cutting blasting: (a) stope 1; (b) stope 2 .

stemming were approximately 30\%, and for stope 2 with composite stemming, they were all less than $10 \%$. There was no clogged blast hole for the third blast in stope 2. Field experimental results indicate that the newly proposed watersoil composite stemming has greatly reduced the clogged blast hole ratio, and this problem, which has long troubled the mine, has been solved. At present, water-soil composite stemming is widely applied in the mine. 


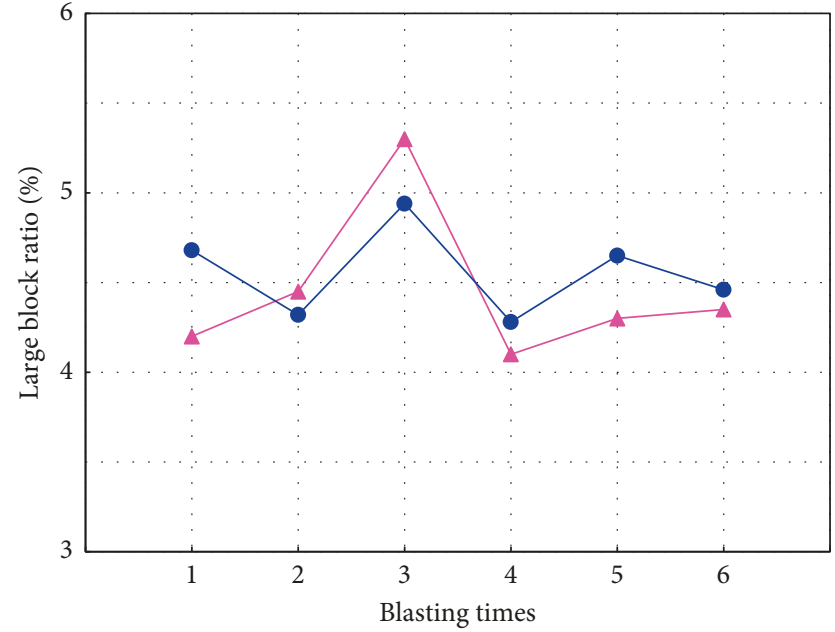

- Stope 1

$\rightarrow$ Stope 2

FIgURE 19: Large block ratios of the stopes.

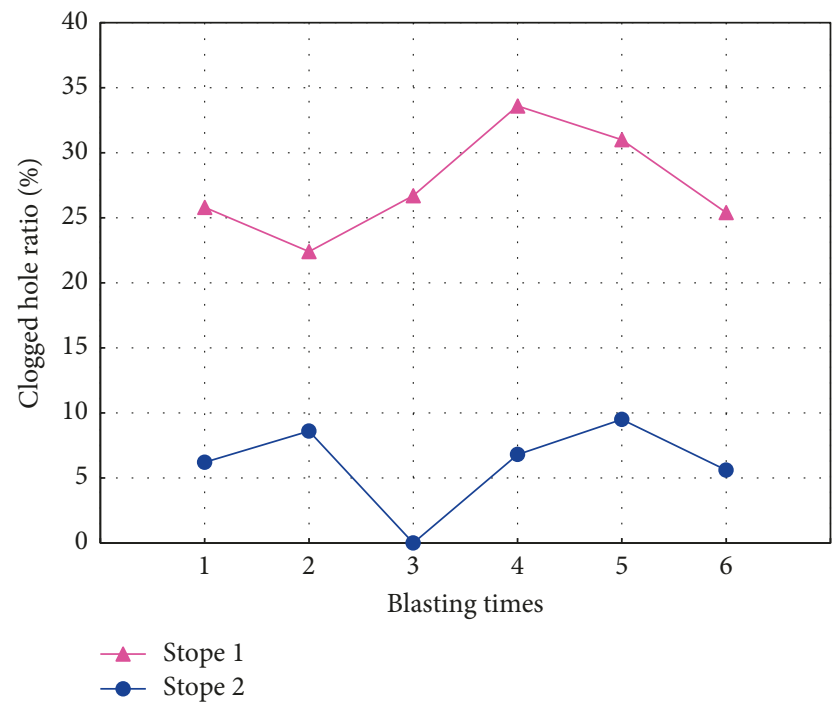

FIgUre 20: Clogged blast hole ratios of the stopes.

\section{Conclusions}

A new water-soil stemming method was proposed to solve the problem of top stemming clogging in large-diameter deep-hole blasting technology in underground mines. Model experiments were first carried out to compare the blasting performance of different types of top stemming. The experimental results indicated that single water stemming was worse at improving the utilization rate of explosion energy compared with single soil stemming with the same length. Further, the mean fragment size decreased with the increase of stemming length for single water stemming. Three schemes of water-soil composite stemming were designed, and the scheme with soil in the lower part and water filled in bags in the higher part had the best fragmentation.
The water-soil composite stemming was applied in an underground stope in the Fankou lead-zinc mine and compared with the traditional single soil stemming. Field tests indicated that the newly proposed water-soil composite stemming did lead to similar rock fragmentation compared with traditional single soil stemming. In addition, the newly proposed water-soil composite stemming greatly reduced the clogged blast hole ratio, from approximately 30\% for single soil stemming to less than $10 \%$, and thus effectively improved blasting and mining efficiency. Further studies will be devoted to exploring new stemming techniques for the purpose of reducing the specific charge.

\section{Conflicts of Interest}

The authors declare that they have no conflicts of interest.

\section{Acknowledgments}

The authors would like to acknowledge the financial support from the National Key Research and Development Program of China (2017YFC0602902), the National Science Foundation of China (51604300), and the Fundamental Research Funds for the Central Universities of Central South University (2016zzts094). The authors are grateful for the support and help from the Fankou lead-zinc mine. The support provided by China Scholarship Council (CSC) during the visit of the first author to Curtin University is acknowledged.

\section{References}

[1] X. Z. Shi, X. Y. Qiu, J. Zhou, X. Chen, Y. Q. Fan, and E. W. Lu, "Application of Hilbert-Huang transform based delay time identification in optimization of short millisecond blasting," Transactions of Nonferrous Metals Society of China, vol. 26, no. 7, pp. 1965-1974, 2016.

[2] J. C. Jhanwar, J. L. Jethwa, and A. H. Reddy, "Influence of airdeck blasting on fragmentation in jointed rocks in an open-pit manganese mine," Engineering Geology, vol. 57, no. 1-2, pp. 13-29, 2000.

[3] B. Bohloli and E. Hoven, "A laboratory and full-scale study on the fragmentation behavior of rocks," Engineering Geology, vol. 89, no. 1-2, pp. 1-8, 2007.

[4] F. P. Zhang, J. Y. Peng, Z. G. Qiu, Q. K. Chen, Y. H. Li, and J. P. Liu, "Rock-like brittle material fragmentation under coupled static stress and spherical charge explosion," Engineering Geology, vol. 220, pp. 266-273, 2017.

[5] X. Z. Shi, X. Y. Qiu, J. Zhou, D. Huang, X. Chen, and Y. G. Gou, "A comparative study of ground and underground vibrations induced by bench blasting," Shock and Vibration, vol. 2016, Article ID 2143575, 9 pages, 2016.

[6] Z. Zhu, "Numerical prediction of crater blasting and bench blasting," International Journal of Rock Mechanics and Mining Sciences, vol. 46, no. 6, pp. 1088-1096, 2009.

[7] S. Bhandari, "On the role of stress waves and quasi-static gas pressure in rock: fragmentation by blasting," Acta Astronautica, vol. 6, no. 3-4, pp. 365-383, 1977.

[8] J. R. Brinkman, "Separating shock waves and gas expansion breakage mechanisms," in Proceedings of the Second International Symposium on Rock Fragmentation by Blasting, Keystone, CO, USA, August 1989. 
[9] H. K. Kutter and C. Fairhurst, "On the fracture process in blasting," International Journal of Rock Mechanics and Mining Sciences \& Geomechanics Abstracts, vol. 8, no. 3, pp. 181-202, 1971.

[10] S. Mchugh, "Crack extension caused by internal gas pressure compared with extension caused by tensile stress," International Journal of Fracture, vol. 21, no. 3, pp. 163-176, 1983.

[11] M. Dobrilovi, Z. Ester, and B. Jankovi, "Measurement in blast hole stem and influence of stemming material on blasting quality," Rudarsko-Geološko-Naftni Zbornik, vol. 17, no. 1, pp. 47-53, 2005.

[12] J. R. Brinkmann, "An experimental study of the effects of shock and gas penetration in blasting," in Proceedings of the 3rd International Symposium on Rock Fragmentation by Blasting, pp. 55-66, Brisbane, Australia, August 1990.

[13] J. L. Floyd, "Explosive energy relief-the key to controlling over break," in Proceedings of the Explosion, pp. 147-153, Kalgoorlie, WA, USA, October 1999.

[14] Q. Zong, "Theoretical discussion of movement rule of stemming in blast holes," Blasting, vol. 13, no. 1, pp. 8-11, 1996.

[15] Y. Luo and S. Wu, "Study on length of stemming material and its effect in hole-charged blasting," Mechanics in Engineering, vol. 28 , no. 2 , pp. $48-52,2006$.

[16] Y. L. Li, X. Z. Shi, B. Liu, and J. P. Zhao, "Experimental research on reasonable length of water stemming," Blasting, vol. 32, no. 2, pp. 11-16, 2015.

[17] H. Cevizci, "A newly developed plaster stemming method for blasting," Journal- South African Institute of Mining and Metallurgy, vol. 112, no. 112, pp. 1071-1078, 2011.

[18] Z. D. Cui, L. Yuan, and C. L. Yan, "Water-silt composite blasting for tunnelling," International Journal of Rock Mechanics and Mining Sciences, vol. 47, no. 6, pp. 1034-1037, 2010.

[19] Z. D. Cui, "Effect of water-silt composite blasting on the stability of rocks surrounding a tunnel," Bulletin of Engineering Geology and the Environment, vol. 70, no. 4, pp. 657-664, 2011.

[20] S. K. Sharma and P. Rai, "Investigation of crushed aggregate as stemming material in bench blasting: a case study," Geotechnical and Geological Engineering, vol. 33, no. 6, pp. 1449-1463, 2015.

[21] P. Manoj, B. Vineeth, and G. K. Pradhan, "Use of discarded water bottles in blasting-an innovative enviro-friendly technique," International Journal of Chemical, Environmental and Biological Sciences, vol. 1, no. 3, pp. 51-56, 2015.

[22] H. Cevizci and H. T. Ozkahraman, "The effect of blast hole stemming length to rockpile fragmentation at limestone quarries," International Journal of Rock Mechanics and Mining Sciences, vol. 53, no. 9, pp. 32-35, 2012.

[23] T. C. Li and H. Q. Liu, "Optimized cut hole stemming length for shaft excavation using one-step deep-hole blasting," Journal of China University of Mining and Technology, vol. 4l, no. 3, pp. 384-389, 2012.

[24] Y. Wang, X. Z. Shi, Y. G. Gou, and T. Guo, "Blast hole stemming length effects of rock blasting with parallel doublefree-surface," Journal of Vibration and Shock, vol. 35, no. 15, pp. 80-85, 2016.

[25] X. Z. Shi, X. Y. Qiu, J. Zhou, J. Nie, and B. H. Li, “Technology and case study of ultra-large section and high shaft excavation by short-millisecond spherical-like blasting," Chinese Journal of Rock Mechanics and Engineering, vol. 35, no. 8, pp. 16591667, 2016.

[26] J. P. Zhao, G. Y. Xu, and K. Huang, "Experimental study on separation and attenuation of blast wave with air decoupling charge," Journal of Central South University (Science and Technology), vol. 42, no. 2, pp. 482-489, 2011. 


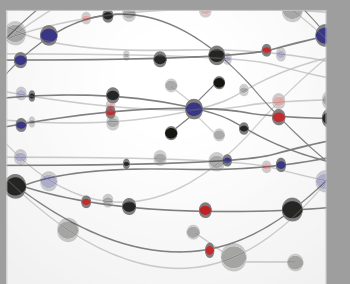

The Scientific World Journal
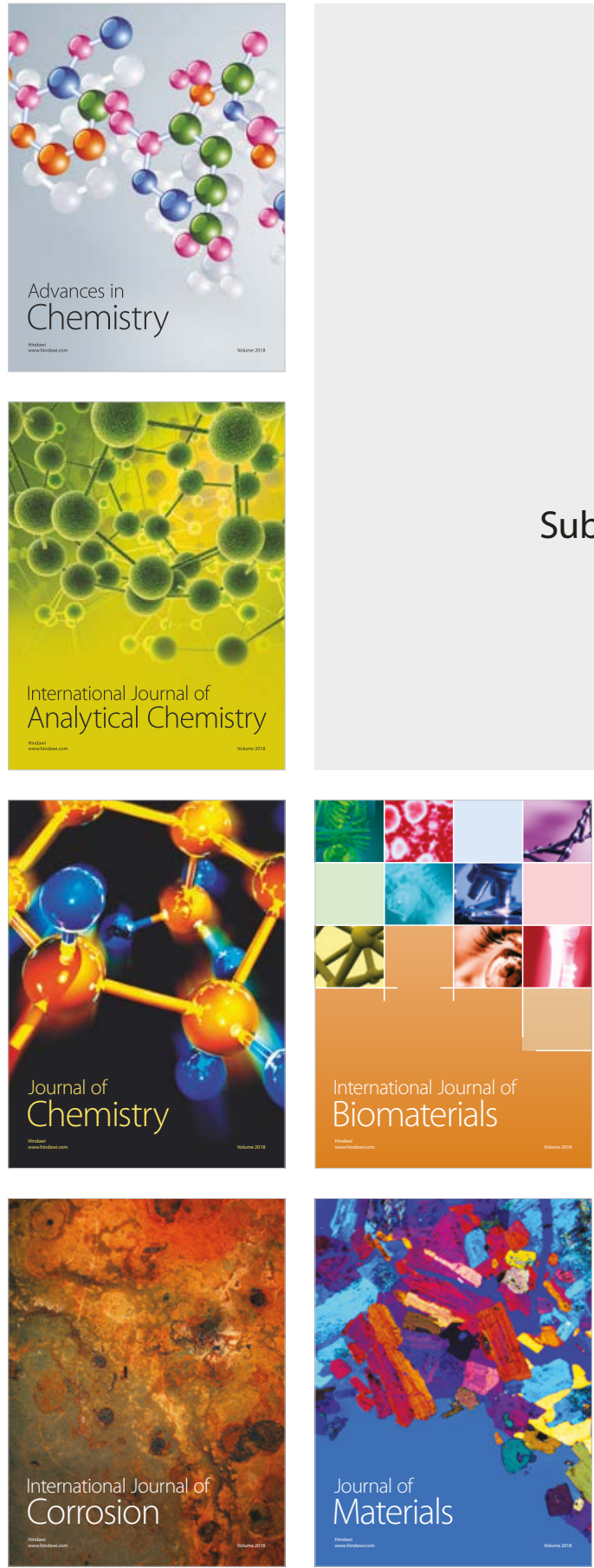

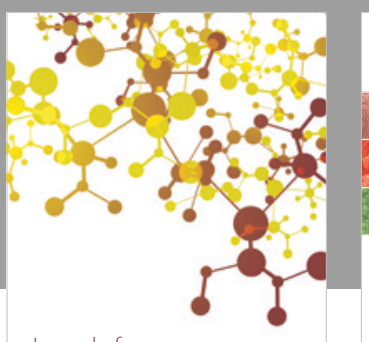

Journal of

Applied Chemistry
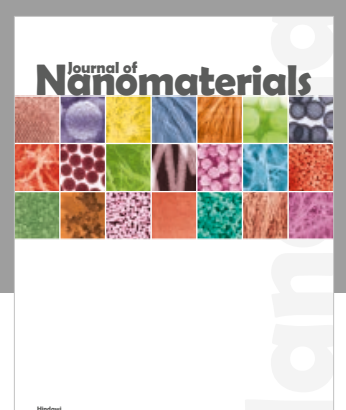

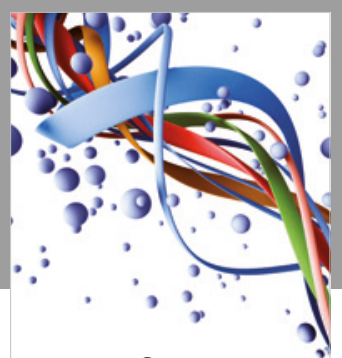

Scientifica

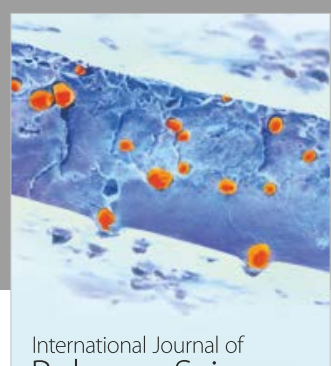

Polymer Science

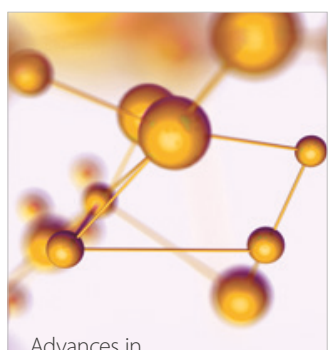

Physical Chemistry
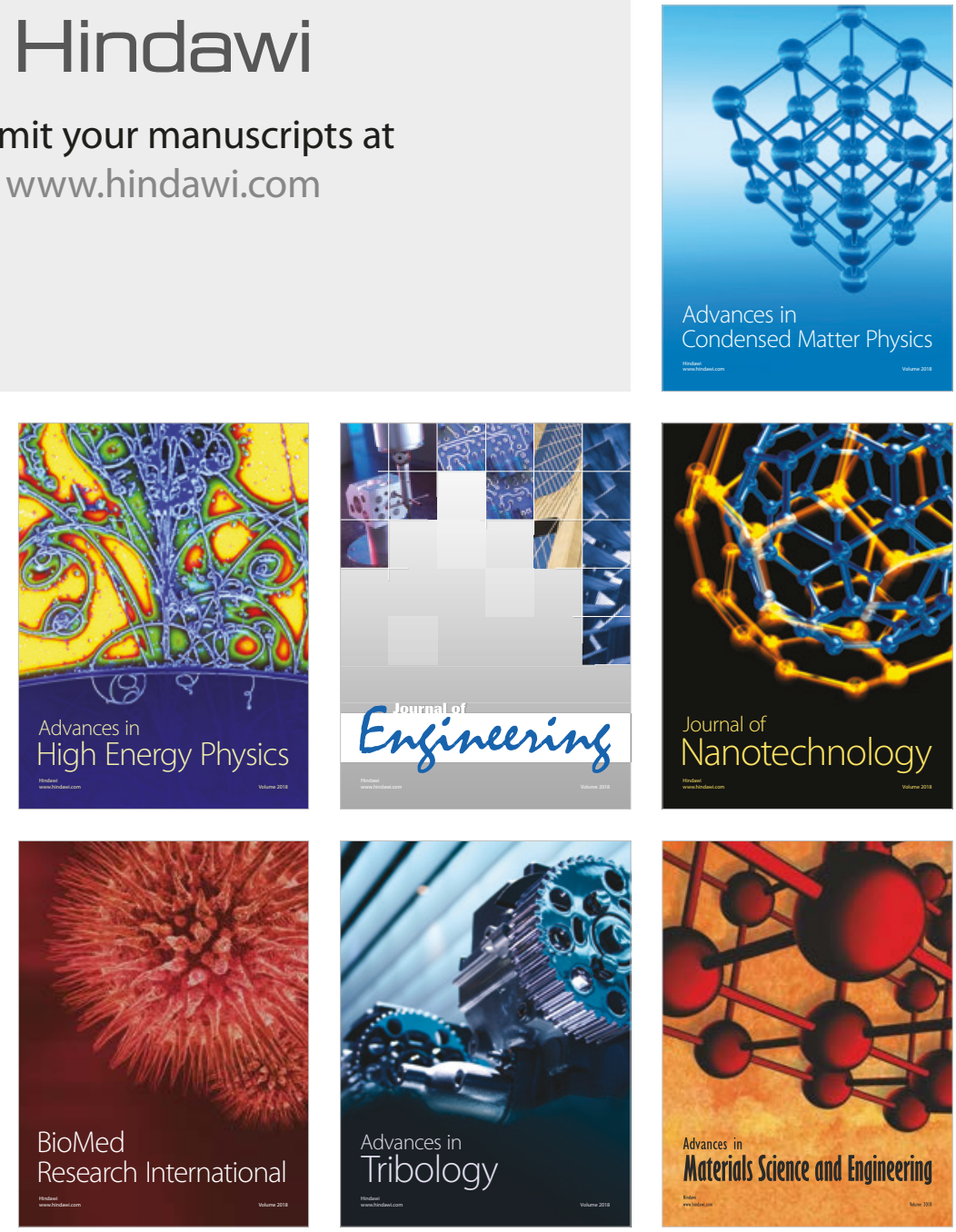